\title{
Time-varying effect and long-term survival analysis in breast cancer patients treated with neoadjuvant chemotherapy
}

\author{
S Baulies ${ }^{1}$, L Belin ${ }^{2}$, P Mallon ${ }^{1,3}$, C Senechal ${ }^{1}$, J-Y Pierga ${ }^{4}$, P Cottu ${ }^{4}$, M-P Sablin ${ }^{4}$, X Sastre ${ }^{5}$, B Asselain ${ }^{2}$, \\ R Rouzier ${ }^{1}$ and F Reyal ${ }^{*}, 1,6,7$
}

${ }^{1}$ Department of Surgery, Institut Curie, 26 rue d'Ulm, 75005 Paris, France; ${ }^{2}$ Department of Biostatistics, Institut Curie, 26 rue d'Ulm, 75005 Paris, France; ${ }^{3}$ Craigavon Area Hospital Breast Unit, Portadown BT63 5QQ, Northern Ireland; ${ }^{4}$ Department of Medical Oncology, Institut Curie, 26 rue d'Ulm, 75005 Paris, France; ${ }^{5}$ Department of Tumor Biology, Institut Curie, 26 rue d'Ulm, 75005 Paris, France; ${ }^{6}$ Department of Translational Research, Residual Tumor and Response to Treatment Lab, RT2Lab, Institut Curie, 26 rue d'Ulm, 75005 Paris, France and 'UMR932, Immunity and Cancer, Institut Curie, 26 rue d'Ulm, 75005 Paris, France

Background: Recent studies have indicated the prognostic value of tumour subtype and pathological complete response (pCR) after neoadjuvant chemotherapy (NAC). However these results were reported after a short follow-up and using a standard Cox model which could be unsatisfactory for time-dependent factors. In the present study, we identified the prognostic factors for long-term outcome after NAC, considering that they could have an inconstant impact over time.

Methods: Prognostic factors from 956 consecutive breast cancer patients treated with NAC were identified and associated with long-term outcomes. We estimated survival by a time function multivariate Cox model regression and stratified by follow-up length.

Results: The prognostic value of tumour histological grade and hormone receptors status varied as distant recurrence-free interval (DRFI) increased. The multivariate analysis identified the following significant prognostic factors: tumour size, N stage, clinical and pathological response to NAC, hormone receptors (HR) status and histological tumour grade. The 'prognostic benefit' of lowgrade and positive-HR status decreased over the years. Thus, in the early years after cancer diagnosis, the hazard ratio of distant recurrences in patients with positive-HR status increased from $0.26(95 \% \mathrm{Cl} 0.1-0.4)$ at 6 months to $2.2(95 \% \mathrm{Cl} 1.3-3.7)$ at 120 months. The histological tumour grade followed a similar trend. The hazard ratio of grade III patients compared with grade I was $1.83(95 \% \mathrm{Cl} 1.1-2.8)$ at 36 months and diminished over time to $0.70(95 \% \mathrm{Cl} 0.4-1.3)$ at 120 months. This indicates that the risk of recurrence for positive-HR patients was 74\% lower at 6 months compared with the negative-hormone receptor group, but 30\% higher at 5 years and more than double at 10 years. High-grade tumours presented a risk of $83 \%$ in the earlier years decreasing to $30 \%$ at 10 years versus the low-grade group.

Conclusion: From the present study, we conclude the importance of identifying time-dependent prognostic factors. Distant recurrence-free interval within women who receive NAC are influenced by achieving $\mathrm{PCR}$ and breast cancer subtype. Tumours with more aggressive biology have poorer survival during the first 5 years, but if they exceed this point their prognostic impact is no longer significant. Conversely, positive-HR patients remain at risk for distant recurrence for many years.

*Correspondence: Dr F Reyal; E-mail: Fabien.reyal@curie.fr

Received 13 January 2015; revised 8 April 2015; accepted 23 April 2015;

published online 16 June 2015

(c) 2015 Cancer Research UK. All rights reserved 0007-0920/15

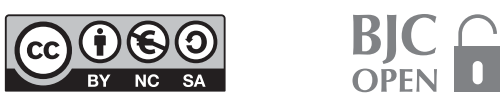


Neoadjuvant chemotherapy (NAC) was initially indicated in patients with advanced breast cancer. It is also being used increasingly in those that present with operable breast cancer but aggressive pathological features (high grade, high proliferation, triple-negative or HER2-positive breast carcinoma). The clinical benefits of NAC are supported by: (a) an increase rate of breastconserving surgery; (b) a similar prognosis of breast cancer patients receiving a neoadjuvant $v s$ an adjuvant therapy regimen; and (c) an accumulation of evidence showing a strong correlation between achieving a pathological complete response (pCR) after neoadjuvant chemotherapy and a good prognosis (Symmans et al, 2007; Gralow et al, 2008; Vargo et al, 2011; Houssami et al, 2012). Von Minckwitz et al (2012) recently reported that patients with luminal A tumour had a 5 -year disease-free survival of $85 \%$, regardless of the pathological response, whereas the survival rate in patients with triple-negative or HER2-positive tumours was significantly different according to the response to systemic treatment. The 5-year disease-free survival in patients with HER2-positive tumour was $90 \%$ in the pCR subgroup vs $60 \%$ in the no pCR subgroup. The 5 -year disease-free survival in patients with triple-negative tumours was $90 \%$ in the pCR subgroup vs $50 \%$ in the no pCR subgroup. Although patients with hormone receptor-positive tumours have a lower pCR rate, their 5-year outcome is favourable, whereas triplenegative and HER2-positive tumours show a high pCR rate but have a worse outcome when they do not achieve a complete response after neoadjuvant chemotherapy (Rouzier et al, 2005; Liedtke et al, 2008; Esserman et al, 2012a). The neoadjuvant setting give a unique opportunity to monitor and study the 'in vivo' tumour sensitivity to one particular treatment.

Several studies have now clearly established the very complex relationship between treatment sensitivity and prognosis. However, to our knowledge, little is known about the long-term prognosis ( $>10$ years) of breast cancer patients treated with neoadjuvant chemotherapy. This analysis has been hampered by multiple factors:

(1) The periodic modification of the neoadjuvant treatment scheme, with the introduction of first generation chemotherapy regimens $(\mathrm{CMF}$-cyclophosphamide $(\mathrm{C})$, methotrexate and fluorouracil), second generation regimens (FEC-fluorouracil, epirubicin (E), C, FAC-fluorouracil, doxorubicin and $\mathrm{C})$, third generation regimens $(\mathrm{EC}-\mathrm{E}$ and $\mathrm{C}, \mathrm{AC}-$ doxorubicin and C, FEC or FAC followed by taxan-based chemotherapy) and the recent introduction of targeted therapy (trastuzumab);

(2) The constant decrease over time of the average tumour size due to the breast cancer screening programme;

(3) The recent identification of the breast cancer molecular subtypes classification that have also been shown to differ in terms of clinical presentation (i.e., axillary lymph node involvement, local and regional recurrence, metastatic delay and patterns, and overall prognosis) and sensitivity to systemic treatment (hormonal therapy, chemotherapy and targeted therapy);

(4) The introduction of adjuvant hormonal therapy (tamoxifen and aromatase inhibitors);

(5) And the improvement of the radiotherapy.

Most prognostic analyses are performed with a standard Cox model but few of them have reported any consideration of the validity of the proportional hazard assumption for each variable tested. This assumption implies that the factors investigated have a constant impact on the hazard over time. Savignoni et al (2012) and Bellera et al (2010) have recently emphasised that this assumption in long-term breast cancer prognostic analysis may be misleading and a significant effect of varying prognostic value of the markers in the early or late follow-up period may be missed.
We intended to study the prognostic determinants over time of a large series of breast cancer patients treated with neoadjuvant chemotherapy at Institut Curie. To accurately decipher the prognostic impact of clinical and pathological factors in this particular breast cancer treatment setting, we performed a prognostic analysis on the whole dataset after a stratification based on the follow-up length (5-year follow-up without distant recurrence).

We first identified the clinical and pathological markers with a time-varying hazard, and they were evaluated to determine the most relevant statistical model, allowing us to perform a time function multivariate Cox model regression analysis.

\section{MATERIALS AND METHODS}

We recorded the experience of neoadjuvant chemotherapy in breast cancer over time at Institute Curie, Paris. From 1981 to 1998, a consecutive series of 956 patients who received neoadjuvant chemotherapy were selected from our prospective Breast Cancer Database.

The selection criteria included prior NAC for operable breast cancer, T2-T3-N0-N1 tumours. Eligibility criteria for NAC included age between 18 and 65 years, OMS status $0-1$, granulocyte count $\geqslant 1500 \mu \mathrm{l}^{-1}$, platelets $\geqslant 100000 \mathrm{l}^{-1}$, haemoglobin level $\geqslant 10 \mathrm{~g} \mathrm{dl}^{-1}$ and adequate liver, renal and cardiac functions. Patients with metastatic, locally advanced or inflammatory breast cancer were excluded, as well as patients with bilateral breast cancer, previous primary tumour and male breast cancer.

Clinical, radiological and pathological data such as patient age, menopausal status, $\mathrm{T}$ stage, $\mathrm{N}$ stage, histological tumour grade, oestrogen receptor (ER), progesterone receptor (PR) and pathological response to NAC were collected through a retrospective review of medical and pathological records. Pretreatment tumour size was assessed by clinical examination and radiographic measurements.

Histological and immunohistochemical study. Pathological diagnosis was confirmed in all patients by pretherapeutic core needle biopsy. Histological grade was performed according to the Elston and Ellis (1991) modification of the Scarff-BloomRichardson grading system. Hormone receptors were analysed by immunohistochemistry. Monoclonal antibodies against ER (clone 6F11, 1/200, Novocastra, Newcastle, UK), and PR (clone $1 \mathrm{~A} 6,1 / 200$, Novocastra) were used to stain the pretreatment core biopsies. Determination was considered positive for ER and PR according to standardised guidelines using a cutoff of $\geqslant 10 \%$ stained tumour nuclei (Balaton et al, 1995; Balaton et al, 1996). Neither HER2 status nor Ki 67 were reported in the study since they were not routinely recorded at that time.

Treatment and follow-up. From 1981 to 1983, chemotherapy consisted of M2AC (doxorubicin $50 \mathrm{mg} \mathrm{m}^{-2}$ on day 1, C $500 \mathrm{mg} \mathrm{m}^{-2}$ on day 1 and methotrexate $25 \mathrm{mg} \mathrm{m}^{-2}$ on days 2 and 9 , and mitomycin $6 \mathrm{mg} \mathrm{m}^{-2}$ on day 1). Beyond 1983, the chemotherapy used was based on FAC or FEC regimen: adryamicin $25 \mathrm{mg} \mathrm{m}^{-2}$ on days 1 and 8 or $\mathrm{E} 50 \mathrm{mg} \mathrm{m}^{-2}$ on day 1 , C $500 \mathrm{mg} \mathrm{m}^{-2}$ on days 1 and 8 ; and 5 -fluorouracil $500 \mathrm{mg} \mathrm{m}^{-2}$ on days 1, 3, 5 and 8. All drugs were administered intravenously.

Patients underwent either mastectomy or breast-conserving surgery (lumpectomy) with axillary lymph node dissection depending on tumour response to NAC. After surgery, adjuvant treatment (local-regional radiotherapy or adjuvant chemotherapy) was given according to Institut Curie's Treatment Guidelines. The adjuvant chemotherapy with FAC or FEC regimen was given according to pathological response to NAC and lymph node status. Tamoxifen was added in all positive-hormone receptor patients as 
adjuvant hormone treatment for the first years of the 2-year treatment period and was extended to 5 years in the mid-1990s.

Once treatment was completed, the patients were followed up every 3 months during the first 2 years, every 6 months for the following 3 years and annually from the fifth year. Clinical examination, mammography and breast ultrasound were performed annually.

Assessment of clinical and pathological response. Clinical response was evaluated by the decrease in tumour volume, complete response (no palpable mass), good partial response (decrease of tumour volume $>50 \%$ ), poor partial response (decrease of tumour volume $<50 \%$ ) and no response (no changes in tumour volume or tumour progression). Pathological response was assessed in post-chemotherapy surgical specimens according to the following classification: Class 1-complete response; Class 2-partial response; Class 3-activity of the tumour (Wolmark et al, 2001).

Statistical analysis. All factors studied are reported in the relevant Tables. The cutoff date for analysis was 24 December 2010.

Distant recurrence-free interval (DRFI) was defined as the time from date of first treatment until the first occurrence of the distant recurrence. Post-metastasis survival (PMS) was defined as the time from distant recurrence until death from any cause. Patients free of event or alive were censored at the date of their last known contact. Survival and interval rates were calculated by the Kaplan-Meier method, and groups were compared using the log-rank test (with no weighting used).

Multivariate analysis was carried out to assess the adjusted influence of prognostic factors using the Cox model (proportional hazards model). The selected covariates for the multivariate analysis were those with a $\log$-rank $P$-value $\leqslant 0.10$ in the univariate analysis. Backward stepwise selection procedure was used.

Proportional hazards hypothesis was tested for each factor using Schoenfeld's residuals test and plotting. When the proportional hazards hypothesis was not satisfied, we introduced a time function to model that time-varying hazard ratio. Cox proportional hazards model allowed us to introduce such factors with time-dependent effects. We tested three different functions relating hazard ratio to time: the linear function, square root function and the log function. To select the most appropriate function, we minimised the Akaike information criterion (AIC). If the AIC of each function was very close, graphical adequacy was used to choose the time function. The time function was included in the Cox model as an interaction term with the factor of interest. Categorical variables were transformed into dummy variables to avoid any assumption concerning the estimation of the relative risks between subgroups. Missing values were coded as separate variables when necessary (MCAR assumption was checked before). Moreover, we introduced locoregional recurrence as a time-dependent factor in the distant recurrence-free interval models. All of the tests were two-tailed and the $P$-value of $<0.05$ indicated significant differences. Analyses were performed using R software, 2.12.1 version (SPSS Statistics, IBM Corporation, Armonk, NY, USA).

\section{RESULTS}

Patient characteristics. A total of 956 patients were included in our study. Patients and tumour characteristics are shown in Table 1 . The median age was 46 years (22-74). About 734 patients were premenopausal (77\%). Median tumour size was $4.5 \mathrm{~cm}$ $(2-15)$. About 676 patients (70\%) had a T2 tumour and 280 had a T3 tumour (29\%). Lymph node involvement was found in 490 patients (44\%). The vast majority of these tumours were infiltrating ductal carcinoma $(88 \%)$, graded II or III (85\%) and positivehormone receptors $(72 \%)$.
Table 1. Clinical and pathological characteristics

\begin{tabular}{|l|c|}
\hline \multicolumn{2}{|c|}{ 956 patients treated with neoadjuvant chemotherapy } \\
\hline Features & N (\%)-Median (range) \\
\hline Age at diagnosis (years) & $46(22-74)$ \\
Premenopausal status & $734(77)$ \\
Tumour size (cm) & $4.5(2-15)$ \\
\hline Tumour stage \\
\hline T2 & $676(71)$ \\
T3 & $280(29)$ \\
\hline N stage \\
\hline NO \\
N1 & $537(56)$ \\
\hline Histological subtypes & $419(44)$ \\
\hline Invasive ductal carcinoma \\
Invasive lobular carcinoma & $730(76)$ \\
Others & $70(7)$ \\
NA & $28(3)$ \\
\hline Histological grade (Elston and Ellis, 1991) \\
\hline I & $128(13)$ \\
II & $115(12)$ \\
III & $380(40)$ \\
NA & $271(28)$ \\
\hline Hormone receptor status & $190(20)$ \\
\hline Positive & \\
Negative & $575(60)$ \\
NA & $225(24)$ \\
\hline Oestrogen receptor status & $156(16)$ \\
\hline Positive \\
Negative & $501(52)$ \\
NA & $297(31)$ \\
\hline Progesterone receptor status & $158(17)$ \\
\hline Positive & $157(16)$ \\
Negative & \\
NA & \\
\hline Abbreviation: NA=not assessed. & $(51)$ \\
\hline
\end{tabular}

The time distribution of patientś initial date of diagnosis was as follows: 177 patients (18\%) were treated between 1986 and 1990, 450 (47\%) between 1991 and 1995, and 329 (34\%) between 1995 and 1998. Statistical significant differences between periods were found in clinical and pathological data at diagnosis.

Treatment and response to neoadjuvant chemotherapy. Patients received during neoadjuvant chemotherapy a median number of 4 cycles (1-6). About $10 \%$ of the patients had a complete clinical response, $52 \%$ had a good partial response, $28 \%$ had a poor partial response and $10 \%$ had no clinical response at the time of surgical procedure. The pCR rate was $9 \%$. Breast-conserving surgery has been performed in $55 \%$ of the cases. Lumpectomy followed by radiotherapy was performed in a total of 429 patients out of the 582 patients $(74 \%)$ who achieved a complete or good partial clinical response, compared with only 95 patients out of the 371 patients (25\%) who achieved a poor partial or no clinical response after neoadjuvant chemotherapy (Supplementary Table 1).

\section{Outcome and prognostic factors}

Time-varying effect analysis. The median follow-up of the whole population analysed was 172 months (6.5-280). Distant recurrence-free interval univariate analyses showed that $\mathrm{T}$ stage, $\mathrm{N}$ stage, histological grade, age at diagnosis $(<35$ years) and both clinical and pathological response were significant prognostic factors. By contrast, no statistically significant differences were found according to tumour hormone receptor status $(P=0.53)$. 
Difference on DRFI according to tumour histological grade and hormone receptors status varies over the years. It was observed that the early survival benefit obtained relating to hormone receptor status decreased over the years and inverted after 10 years, and a similar pattern was observed with histological tumour grade (Figure 1).

The proportional hazards hypothesis was not satisfied for both of them. To model the hazard ratio evolved over time, a logarithmic running-time function was used for hormone receptor status and for histological grade. The multivariate analysis identified the following significant prognostic factors for distant recurrence-free interval: tumour size, $\mathrm{N}$ stage, clinical and pathological response to NAC, hormone receptors status and histological tumour grade (Table 2). The 'prognostic benefit' of low-grade and positive-hormone receptor status decreased over the years. Thus, in the early years after cancer diagnosis, the hazard ratio of distant recurrences of patients with positive-hormone receptor status increased from $0.26(95 \%$ CI $0.1-0.4)$ at 6 months to 0.93 (95\% CI $0.7-1.2)$ at 36 months. Beyond this time point, the hazard ratio continued increasing from 1.3 (95\% CI 0.9-1.9) at 60 months to 2.2 (95\% CI $1.3-3.7)$ at 120 months. The histological tumour grade followed a similar trend. The hazard ratio of grade III patients compared with grade I was 1.83 (95\% CI 1.15-2.89) at 36 months and diminished over time to 0.70 (95\% CI $0.38-1.27)$ at 120 months.

This indicates that the risk of recurrence for positive-HR patients was $74 \%$ lower at 6 months compared with the negativehormone receptor group, but $30 \%$ higher at 5 years and more than double at 10 years. High-grade tumours presented a recurrence risk of $83 \%$ in the earlier years decreasing to $30 \%$ at 10 years $v$ s the lowgrade group.

Time period analysis. We analysed the DRFI adjusted to time period. The chosen cutoff was 60 months (5 years). Univariate analyses for the first 5 years indicated that negative-hormone receptor status, larger clinical $\mathrm{T}$ stage, $\mathrm{N}$ stage, high histologic grade and no clinical response and no pathological response were correlated to poorer DRFI. A multivariate analysis was performed. All variables were independent prognostic factors: $T$ stage $(P=0.011), \quad \mathrm{N}$ stage $(P<0.001)$, hormone receptor status $(P=0.037)$, histological grade $(P=0.001)$, clinical response $(P=0.003)$ and pathological response $(P<0.001)$ (Table 3$)$. In the first 5 years of follow-up, hazard ratio for positive-hormone receptors patients was 0.67 (95\% CI $0.50-0.91)$.

A subgroup of 622 patients who had survived beyond the first 5 years without distant recurrence was identified. We investigated their prognostic factors over the first 5 years. Lymph node status, hormone receptor and clinical and pathological responses to neoadjuvant chemotherapy remained statistically significant prognostic factors (Table 4). After the first 5 years of follow-up, the hazard ratio for positive-hormone receptor patients was 1.55 (95\% CI 0.94-2.55).

Prognostic impact of locoregional recurrence. To analyse the prognostic impact of locoregional recurrence, we performed the same analysis within the subset of patients treated with lumpectomy. Patients treated with total mastectomy were excluded from this analysis. Patients and tumour characteristics are shown in Supplementary Table 2. Age at diagnosis, T stage and clinical response were not significant variables. Difference on DRFI according to tumour histological grade and hormone receptors status varied over time. The proportional hazards hypothesis was not satisfied for both of them. To model the evolution of the hazard ratio, a logarithmic running-time function was used. The multivariate analysis showed that $\mathrm{N}$ stage, histological grade, hormone receptor status, pathological response and locoregional recurrence were significantly related to the prognosis (Table 5).
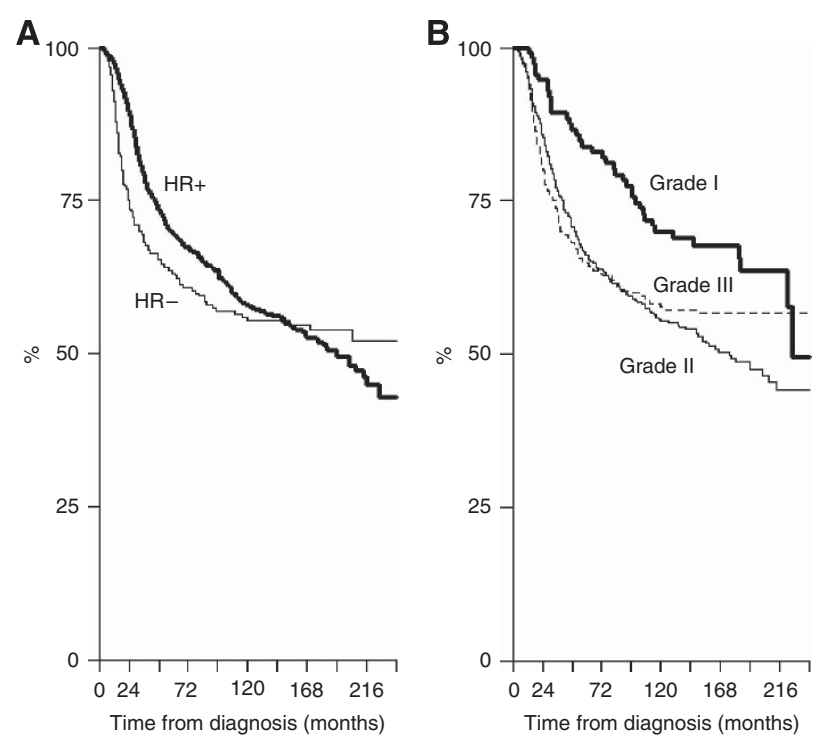

Figure 1. Distant recurrence-free interval according to (A) hormonal receptor status, and (B) histologic grade.

Table 2. Prognostic factors for DRFI (multivariate analysis)

\begin{tabular}{|l|c|c|c|c|}
\hline \multicolumn{5}{|c|}{ DRFI multivariate analysis } \\
\hline Characteristics & Time (months) & HR & $95 \%$ Cl & $P$-value \\
\hline Tumour stage \\
\hline T2 & & 1 & - & \\
T3 & 1.26 & $1.01-1.57$ & 0.048 \\
\hline
\end{tabular}

\section{$\mathrm{N}$ stage}

\begin{tabular}{|l|c|c|c|c|}
\hline N0 & & 1 & - & \\
N1 & & 1.82 & $1.48-2.24$ & $<0.001$ \\
\hline
\end{tabular}

\section{Histological grade} I 11 III

\begin{tabular}{c|c|c|c|}
60 & 1.59 & $1.09-2.31$ \\
6 & 7.05 & $0.63-1.74$ \\
& & & $2.38-$ \\
& & 22.20 \\
& & 1.83 & $1.15-2.87$ \\
60 & 1.22 & $0.80-1.87$ \\
120 & 0.70 & $0.39-1.28$
\end{tabular}

\begin{tabular}{|l|c|c|c|c|}
\hline Hormone receptor \\
\hline Negative & 6 & 1 & - & $<0.001$ \\
Positive & 36 & 0.25 & $0.14-0.45$ & \\
& 60 & 0.93 & $0.7-1.22$ & \\
& 120 & 2.34 & $0.94-1.91$ & \\
\hline & & 2.22 & $1.32-3.74$ & \\
\end{tabular}

\section{Clinical response}

\begin{tabular}{|l|c|c|c|c|}
\hline Complete & & 0.88 & $0.58-1.33$ & 0.001 \\
Partial & & 1 & - & \\
Nonresponse & & 1.75 & $1.31-2.34$ & \\
\hline
\end{tabular}

Pathological response

\begin{tabular}{|l|c|c|c|c|}
\hline $\mathrm{PPR} / \mathrm{pNR}$ & 1 & - & $<0.001$ \\
$\mathrm{PCR}$ & & 0.32 & $0.19-0.55$ & \\
\hline
\end{tabular}

Abbreviations: $\mathrm{Cl}=$ confidence interval; $\mathrm{DRFI}=$ distant recurrence-free interval; $\mathrm{pCR}=$ pathological complete response; $\mathrm{pNR}=$ pathological non response; $\mathrm{PPR}=$ pathological partial response.

${ }^{a} N=956$ patients treated by neoadjuvant chemotherapy. Log time function introduction for histological grade and hormonal receptor status. 
Post-metastases survival. Both univariate and multivariate studies confirmed the associations of positive-hormone receptor status (HR 0.49; 95\% CI 0.3-0.63; $P<0.0001$ ) and high histologic grade (HR 1.8; 95\% CI 0.95-2.13; $P=0.0027$ ) with PMS (Figures 2 and 3 ). In contrast, response to NAC (clinical and pathological response) ceased to be a prognostic factor for outcome after metastases.

\begin{tabular}{|c|c|c|c|}
\hline \multicolumn{4}{|c|}{ First 5-year DRFI multivariate analysis ${ }^{a}$} \\
\hline Characteristics & RR & $95 \% \mathrm{Cl}$ & $P$-value \\
\hline \multicolumn{4}{|l|}{ Tumour stage } \\
\hline $\begin{array}{l}\text { T2 } \\
\text { T3 }\end{array}$ & $\begin{array}{c}1 \\
1.41\end{array}$ & $\frac{-}{1.09-1.83}$ & $\overline{0.011}$ \\
\hline \multicolumn{4}{|l|}{$\mathrm{N}$ stage } \\
\hline $\begin{array}{l}\text { N0 } \\
\text { N1 }\end{array}$ & $\begin{array}{c}1 \\
1.85\end{array}$ & $\frac{-}{1.45-2.38}$ & $-\overline{0.001}$ \\
\hline \multicolumn{4}{|c|}{ Histological grade } \\
\hline $\begin{array}{l}\text { I } \\
\text { II } \\
\text { III }\end{array}$ & $\begin{array}{c}1 \\
2.53 \\
2.40\end{array}$ & $\begin{array}{c}- \\
1.58-4.29 \\
1.39-4.13\end{array}$ & $\begin{array}{c}0.001 \\
- \\
-\end{array}$ \\
\hline \multicolumn{4}{|c|}{ Hormone receptor } \\
\hline $\begin{array}{l}\text { Negative } \\
\text { Positive }\end{array}$ & $\begin{array}{c}1 \\
0.67\end{array}$ & $\frac{-}{0.50-0.91}$ & 0.037 \\
\hline \multicolumn{4}{|l|}{ Clinical response } \\
\hline $\begin{array}{l}\text { Complete } \\
\text { Partial } \\
\text { Nonresponse }\end{array}$ & $\begin{array}{l}1.08 \\
1 \\
1.91\end{array}$ & $\begin{array}{c}0.69-1.71 \\
- \\
1.35-2.69\end{array}$ & $\begin{array}{c}0.003 \\
- \\
-\end{array}$ \\
\hline \multicolumn{4}{|c|}{ Pathological response } \\
\hline $\begin{array}{l}\text { pCR } \\
\text { pPR/pNR }\end{array}$ & $\begin{array}{c}0.31 \\
1\end{array}$ & $\begin{array}{c}0.16-0.59 \\
-\end{array}$ & $<0.001$ \\
\hline \multicolumn{4}{|c|}{$\begin{array}{l}\text { Abbreviations: } \mathrm{Cl}=\text { confidence interval; } \mathrm{DRFI}=\text { distant recurrence-free interval; } \mathrm{PCR}= \\
\text { pathological complete response; } \mathrm{pNR}=\text { pathological nonresponse; } \mathrm{PPR}=\text { pathologica } \\
\text { partial response; } \mathrm{RR}=\text { relative risk. } \\
{ }^{\mathrm{a}} \mathrm{N}=956 \text { patients treated with neoadjuvant chemotherapy. }\end{array}$} \\
\hline
\end{tabular}

Table 4. Prognostic factors for DRFI in the 5-year no distant recurrence subgroup (multivariate analysis)

\begin{tabular}{|c|c|c|c|}
\hline \multicolumn{4}{|c|}{ DRFI multivariate analysis ${ }^{a}$} \\
\hline Characteristics & RR & $95 \% \mathrm{Cl}$ & $P$-value \\
\hline \multicolumn{4}{|c|}{ Lymph node status } \\
\hline NO & 1 & - & \multirow[t]{2}{*}{0.028} \\
\hline N1 & 1.49 & $1.04-2.11$ & \\
\hline \multicolumn{4}{|c|}{ Hormone receptor } \\
\hline Negative & 1 & - & \multirow[t]{2}{*}{0.035} \\
\hline Positive & 1.55 & $0.94-2.55$ & \\
\hline \multicolumn{4}{|l|}{ Clinical response } \\
\hline Complete & 0.46 & $0.2-1.06$ & \multirow[t]{3}{*}{0.021} \\
\hline Partial & 1 & - & \\
\hline Non response & 1.59 & $0.96-2.64$ & \\
\hline \multicolumn{4}{|c|}{ Pathological response } \\
\hline $\mathrm{pCR}$ & 0.34 & $0.12-0.92$ & 0.044 \\
\hline $\mathrm{pPR} / \mathrm{pNR}$ & 1 & - & \\
\hline \multicolumn{4}{|c|}{$\begin{array}{l}\text { Abbreviations: } \mathrm{Cl}=\text { confidence interval; } \mathrm{DRFI}=\text { distant recurrence-free interval; } \mathrm{pCR}= \\
\text { pathological complete response; } \mathrm{pNR}=\text { pathological non response; } \mathrm{pPR}=\text { pathological } \\
\text { partial response. } \\
{ }^{\mathrm{a}} \mathrm{N}=622 \text { patients treated by } \mathrm{NAC} \text { and no distant recurrence at } 5 \text { years. }\end{array}$} \\
\hline
\end{tabular}

Table 5. DRFI multivariate analysis in $\mathbf{5 2 5}$ patients initially treated by neoadjuvant chemotherapy followed by lumpectomy plus axillary lymph node dissection

\begin{tabular}{|c|c|c|c|c|}
\hline \multicolumn{5}{|c|}{ DRFI multivariate analysis ${ }^{a}$} \\
\hline Characteristics & Time (months) & HR & $95 \% \mathrm{Cl}$ & $P$-value \\
\hline \multicolumn{5}{|c|}{ Lymph node status } \\
\hline $\begin{array}{l}\text { N0 } \\
\text { N1 }\end{array}$ & & $\begin{array}{c}1 \\
1.47\end{array}$ & $\frac{-}{1.08-1.99}$ & 0.015 \\
\hline \multicolumn{5}{|c|}{ Histological grade } \\
\hline $\begin{array}{l}\text { I } \\
\text { II }\end{array}$ & $\begin{array}{c}6 \\
\\
36 \\
60 \\
120 \\
6 \\
\\
36 \\
60 \\
120\end{array}$ & \begin{tabular}{l|}
1 \\
6.96 \\
\\
\\
1.63 \\
1.07 \\
0.61 \\
5.94 \\
\\
\\
\\
2.84 \\
2.3 \\
1.73
\end{tabular} & $\begin{array}{c}\overline{1} \\
1.03- \\
46.93 \\
0.78-3.38 \\
0.57-2.02 \\
0.26-1.45 \\
0.86- \\
40.97 \\
1.35-5.97 \\
1.24-4.26 \\
0.77-3.89\end{array}$ & 0.006 \\
\hline \multicolumn{5}{|c|}{ Hormone receptor } \\
\hline $\begin{array}{l}\text { Negative } \\
\text { Positive }\end{array}$ & $\begin{array}{l}6 \\
36 \\
60 \\
120\end{array}$ & $\begin{array}{c}1 \\
0.67 \\
0.82 \\
0.87 \\
0.94 \\
\end{array}$ & $\begin{array}{c}- \\
0.20-2.23 \\
0.49-1.36 \\
0.45-1.68 \\
0.34-2.60\end{array}$ & 0.02 \\
\hline \multicolumn{5}{|c|}{ Pathological response } \\
\hline $\begin{array}{l}\mathrm{pPR} / \mathrm{pNR} \\
\mathrm{pCR}\end{array}$ & & $\begin{array}{c}1 \\
0.33\end{array}$ & $\frac{-}{0.17-0.62}$ & $<0.001$ \\
\hline \multicolumn{5}{|c|}{ Locoregional relapse } \\
\hline $\begin{array}{l}\text { No } \\
\text { Yes }\end{array}$ & & $\begin{array}{c}1 \\
4.21\end{array}$ & $2.89-6.11$ & $<0.001$ \\
\hline \multicolumn{5}{|c|}{$\begin{array}{l}\text { Abbreviations: } \mathrm{Cl}=\text { confidence interval; } \mathrm{DRFI}=\text { distant recurrence-free interval; } \mathrm{pCR}= \\
\text { pathological complete response; } \mathrm{pNR}=\text { pathological non response; } \mathrm{PPR}=\text { pathological } \\
\text { partial response. } \\
\mathrm{a}_{N=525} \text { patients treated by neoadjuvant chemotherapy and lumpectomy. Log time } \\
\text { function introduction for histological grade and hormonal receptor status. }\end{array}$} \\
\hline
\end{tabular}

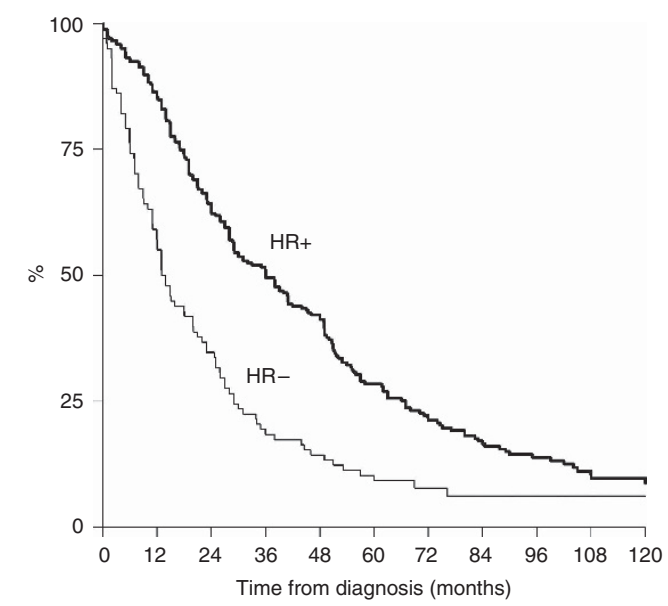

Figure 2. Post-metastases survival according to hormonal receptor status.

\section{DISCUSSION}

The present study intended to analyse the prognostic determinants over time of a large series of 956 breast cancer patients treated with neoadjuvant chemotherapy at Institut Curie from 1981 to 1998. The median follow-up was 172 months (6.47-280). Many studies, 


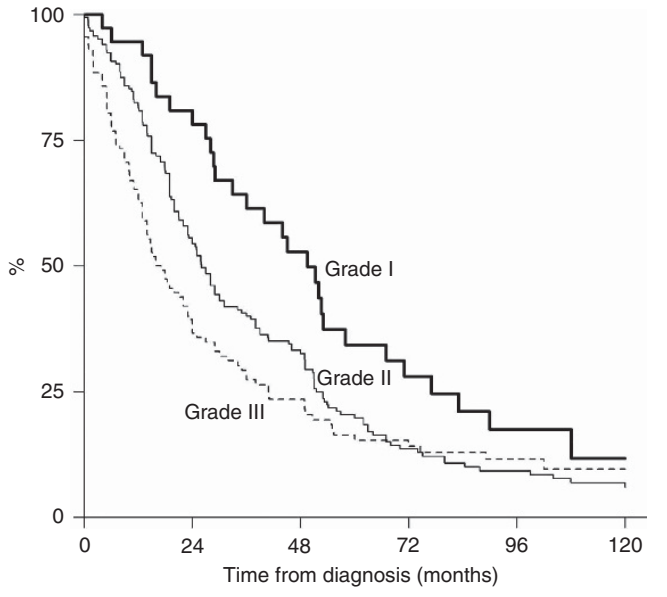

Figure 3. Post-metastases survival according to histologic grade. Dashed line: Grade I; dotted line: Grade III.

using a standard Cox model, have previously identified that proliferation, lymph node status, tumour size and hormone receptor status were strong and significant prognostic factors (Dunnwald and Rossing Ma, 2007; Soerjomataram et al, 2008).

However, Savignoni et al (2012) showed that estimating the prognostic effect of a time-dependent covariate could be unsatisfactory using a standard Cox model. We showed that hormone receptors and histological grade were time-dependent factors and a running-time function was applied to them. Thus, in our results, positive-hormone receptor and low-grade tumours defined a good prognostic subgroup in early years, but beyond 5 years the distant recurrence-free interval became shorter. We identified a hazard ratio for distant recurrence from 0.26 (95\% CI $0.14-0.46)$ at 6 months to 2.19 (95\% CI 1.29-3.71) at 120 months in HR-positive patients. In contrast, grade III tumours had a 7.17 (95\% CI 2.24-22.92) hazard ratio at 6 months vs a 0.65 (95\% CI $0.35-1.19)$ hazard ratio at 120 months. These results are of interest as hormone receptor positive, and low histological grade tumours have been considered as tumours with a good outcome (Esserman et al, 2012a).

The earlier diagnosis and the increasing use of systemic therapy in clinical practice have contributed to improved breast cancer outcome at a population level. Approximately $80 \%$ of women with primary breast cancer are expected to survive for at least 10 years after the operation (mastectomy or breastconserving surgery). However, among patients who have a relapse after the operation, only about $5 \%$ survive for $>10$ years (Rahman et al, 1999; Clarke et al, 2005). For women with positive-ER breast cancer, treatment for 5 years with adjuvant tamoxifen substantially reduces the rate of recurrence not only during the treatment period but throughout the first decade. However, it has been shown that patients treated with tamoxifen continue to recur late, and the benefit of adjuvant hormonal therapy is gone after 15 years (Clarke et al, 2005). Recently, the ATLAS trial demonstrated that additional years of adjuvant endocrine therapy for premenopausal women who have completed 5 years of tamoxifen treatment decreased the recurrence and mortality rates (Davies et al, 2013).

Breast cancer is a heterogeneous disease and patients with similar tumour histology may have different prognoses (Gralow et al, 2008; Meyers et al, 2011; Esserman et al, 2012b). The importance of underlying tumour biology in predicting outcomes has been demonstrated by identifying various molecular subtypes. At this point, neoadjuvant treatment allows us to evaluate 'in vivo' sensitivity to treatment. Rouzier et al (2005) was the first to describe that breast cancer molecular subtypes responded differently to preoperative chemotherapy . Clinical and pathological responses have been used as surrogate prognostic factors. Patients who achieved a complete response not only potentially benefit from breast-conserving treatment but also present a better prognosis (Pierga et al, 2003; Von Minckwitz et al, 2012). Von Minckwitz et al (2012) clearly showed with triple-negative and HER2-positive tumours a strong correlation between achieving a pCR and a good outcome; however, pCR was not correlated to a good outcome in the luminal subgroup. By contrast, our study identified pCR as a positive long-term prognostic factor in both positive and negative-hormone receptor subgroups. Our results are in agreement with those recently presented by Cortazar et al (2014) showing in a large series of neoadjuvant-treated breast cancer that pCR was associated to a favourable outcome even in the luminal subset. Pathological complete response is a strong prognostic factor for evaluating survival but its impact disappeared within the patients who had already presented metastases. In our series, the only independent factors for PMS were positive-hormone receptor status (HR 0.49, 95\% CI 0.3-0.63) and high histological grade (HR 1.8, 95\% CI 0.95-2.13).

A considerable number of women still remain at risk for early or late locoregional recurrences. Time to recurrence is a prognostic factor that remains controversial (Lee et al, 2011). Some studies have reported that outcome is better within patients with late recurrence ( $>3$ years) than those patients with early recurrence, whereas other analysis showed no significant effect of local recurrence-free time and outcome (Fredriksson et al, 2002; Wapnir et al, 2006; Lukens et al, 2009).

In our study locoregional recurrence was included as a timevarying covariate, but it could also be considered as a competing event of distant recurrence and could be modelled using the Fine and Gray (1999). Our results showed local recurrence among patients treated with conservative surgery within the first 5 years was a strong prognostic factor of developing distant metastases (HR 4.21; 95\% CI 2.89-6.11; $P<0.001$ ). An early local recurrence is probably related to a higher biological aggressiveness and a greater chemo-resistance.

From the present study, we conclude the importance of identifying time-dependent prognostic factors. Distant recurrence-free interval within women who receive NAC is influenced by achieving pCR and breast cancer subtype. Tumours with more aggressive biology have poorer survival during the first 5 years, but if they exceed this point their prognostic effect was no longer significant. Conversely, HR-positive patients remain at risk for distant recurrence for many years. Early locoregional recurrence within 5 years following diagnosis was a strong independent prognostic marker of DRFI, whereas survival among patients with late recurrence did not differ from those who never experienced a recurrence.

\section{REFERENCES}

Balaton AJ, Baviera EE, Galet B, Vaury P, Vuong PN (1995)

[Immunohistochemical evaluation of estrogen and progesterone receptors on paraffin sections of breast carcinomas. Practical thoughts based on the study of 368 cases]. Arch Anat Cytol Pathol 43: 93-100.

Balaton AL, Coindre JM, Collin F, Ettore F, Fiche M, Jacquemier J, Le Doussal V, Mandard AM, Mathieu MC, Migeon C, Simony-Lafontaine J, Treilleux I, Verriele V, Vilain MO, Zafrani B (1996) [Recommendations for the immunohistochemical evaluation of hormone receptors on paraffin sections of breast cancer. Study Group on Hormone Receptors using Immunohistochemistry FNCLCC/AFAQAP. National Federation of Centres to Combat Cancer/French Association for Quality Assurance in Pathology]. Ann Pathol 16: 144-148.

Bellera CA, MacGrogan G, Debled M, de Lara CT, Brouste V, MathoulinPélissier S (2010) Variables with time-varying effects and the cox model: some statistical concepts illustrated with a prognostic factor study in breast cancer. BMC Med Res Methodol 10: 20. 
Clarke M, Collins R, Darby S, Davies C, Evans V, Godwin J (2005) Effects of chemotherapy and hormonal therapy for early breast cancer on recurrence and 15-year survival: an overview of the randomised trials. Lancet 365 : $1687-1717$.

Cortazar P, Zhang L, Untch M, Mehta K, Costantino JP, Wolmark N, Bonnefoi H, Cameron D, Gianni L, Valagussa P, Swain SM, Prowell T, Loibl S, Wickerham DL, Bogaerts J, Baselga J, Perou C, Blumenthal G, Blohmer J, Mamounas EP, Bergh J, Semiglazov V, Justice R, Eidtmann H, Paik S, Piccart M, Sridhara R, Fasching PA, Slaets L, Tang S, Gerber B, Geyer Jr CE, Pazdur R, Ditsch N, Rastogi P, Eiermann W, von Minckwitz G (2014) Pathological complete response and long-term clinical benefit in breast cancer: the CTNeoBC pooled analysis. Lancet 384: 164-172.

Davies C, Pan H, Godwin J, Gray R, Arriagada R, Raina V, Abraham M, Medeiros Alencar VH, Badran A, Bonfill X, Bradbury J, Clarke M, Collins R, Davis SR, Delmestri A, Forbes JF, Haddad P, Hou MF, Inbar M, Khaled H, Kielanowska J, Kwan WH, Mathew BS, Mittra I, Müller B, Nicolucci A, Peralta O, Pernas F, Petruzelka L, Pienkowski T, Radhika R, Rajan B, Rubach MT, Tort S, Urrútia G, Valentini M, Wang Y, Peto R. Adjuvant Tamoxifen: Longer Against Shorter (ATLAS) Collaborative Group (2013) Long-term effects of continuing adjuvant tamoxifen to 10 years $v s$ stopping at 5 years after diagnosis of oestrogen receptor-positive breast cancer: ATLAS, a randomised trial. Lancet 381: 805-816.

Dunnwald LK, Rossing Ma Li Cl (2007) Hormone receptor status, tumor characteristics, and prognosis: a prospective cohort of breast cancer patients. Br Cancer Res 9(1): R6.

Elston CW, Ellis IO (1991) Pathological prognostic factors in breast cancer. I. The value of histological grade in breast cancer: experience from a large study with long-term follow-up. Histopathology 19: 403-410.

Esserman LJ, Berry DA, DeMichele A, Carey L, Davis SE, Buxton M, Hudis C, Gray JW, Perou C, Yau C, Livasy C, Krontiras H, Montgomery L, Tripathy D, Lehman C, Liu MC, Olopade OI, Rugo HS, Carpenter JT, Dressler L, Chhieng D, Singh B, Mies C, Rabban J, Chen YY, Giri D, van 't Veer L, Hylton N (2012a) Pathologic complete response predicts recurrence-free survival more effectively by cancer subset: results from the I-SPY 1 TRIAL. J Clin Oncol 30: 3242-3249.

Esserman LJ, Berry DA, Cheang MC, Yau C, Perou CM, Carey L, DeMichele A, Gray JW, Conway-Dorsey K, Lenburg ME, Buxton MB, Davis SE, van't Veer LJ, Hudis C, Chin K, Wolf D, Krontiras H, Montgomery L, Tripathy D, Lehman C, Liu MC, Olopade OI, Rugo HS, Carpenter JT, Livasy C, Dressler L, Chhieng D, Singh B, Mies C, Rabban J, Chen YY, Giri D, Au A, Hylton N. I-SPY 1 TRIAL Investigators (2012b) Chemotherapy response and recurrence-free survival in neoadjuvant breast cancer depens on biomarker profiles: results from the I-SPY 1 TRIAL. Breast Cancer Res Treat 132: 1049-1062.

Fine J, Gray R (1999) A proportional hazards model for the subdistribution of a competing risk. J Am Stat Assoc 94: 496-509.

Fredriksson I, Liljegren G, Arnesson LG, Emdin SO, Palm-Sjövall M, Fornander T, Holmqvist M, Holmberg L, Frisell J (2002) Local recurrence in the breast after conservative surgery- a study of prognosis and prognostic factors in 391 women. Eur J Cancer 38: 1860-1870.

Gralow JR, Burstein HJ, Wood W, Hortobagyi GN, Gianni L, von Minckwitz G, Buzdar AU, Smith IE, Symmans WF, Singh B, Winer EP (2008) Preoperative therapy in invasive breast cancer: pathologic assessment and systemic therapy issues in operable disease. J Clin Oncol 26: 814-819.

Houssami N, Macaskill P, Von Minckwitz G, Marinovich ML, Mamounas E (2012) Meta-analysis of the association of breast cancet subtype and pathologic complete response toneoadjuvant chemotherapy. Eur J Cancer 48: 3342-3354.

Lee JS, Kim SI, Park HS, Lee JS, Park S, Park BW (2011) The impact of local and regional recurrence on distant metastasis and survival in patients treated with breast conservation therapy. J Br Cancer 14: 191-197.
Liedtke C, Mazouni C, Hess KR, André F, Tordai A, Mejia JA, Symmans WF, Gonzalez-Angulo AM, Hennessy B, Green M, Cristofanilli M, Hortobagyi GN, Pusztai L (2008) Response to neoadjuvant therapy and long-term survival in patients with triple-negative breast cancer. J Clin Oncol 26: 1275-1281.

Lukens JN, Vapiwala N, Hwang WT, Solin LJ (2009) Regional nodal recurrence after breast conservation treatment with radiotherapy for women with early-stage breast carcinoma. Int J Radiat Oncol Biol Phys 73: 1475-1481.

Meyers MO, Klauber-Demore N, Ollila DW, Amos KD, Moore DT, Drobish AA, Burrows EM, Dees EC, Carey LA (2011) Impact of breast cancer molecular subtypes on locorregional recurrence in patients treated with neoadjuvant chemotherapy for locally advanced breast cancer. Ann Surg Oncol 18: 2851-2857.

Pierga JY, Mouret E, Laurence V, Diéras V, Savigioni A, Beuzeboc P, Dorval T, Palangié T, Jouve M, Pouillart P (2003) Prognostic factors for survival after neoadjuvant chemotherapy in operable breast cancer: the role of clinical response. Eur J Cancer 39: 1089-1096.

Rahman ZU, Frye DK, Smith TL, Asmar L, Theriault LA, Buzdar AU, Hortbagyi GN (1999) Results and long term follow-up for 1581 patients with metastatic breast carcinoma treated with standard dose doxorubicincontaining chemotherapy: a reference. Cancer 85: 104-111.

Rouzier R, Perou CM, Symmans WF, Ibrahim N, Cristofanilli M, Anderson K, Hess KR, Stec J, Ayers M, Wagner P, Morandi P, Fan C, Rabiul I, Ross JS, Hortobagyi GN, Pusztai L (2005) Breast cancer molecular subtypes respond differently to preoperative chemotherapy. Clin Cancer Res 11: $5678-5685$.

Savignoni A, Hajage D, Tubert-Bitter P, De Rycke Y (2012) Effect of an event occurring over time and confounded by health status: estimation and interpretation. A study based on survival data stimulations with application on breast cancer. Stat Med 31: 4444-4455.

Soerjomataram I, Louwman MW, Ribot JG, Roukema JA, Coebergh JW (2008) An overview of prognostic factors for long-term survivors of breast cancer. Br Cancer Res Treat 107: 309-330.

Symmans WF, Peintinger F, Hatzis C, Rajan R, Kuerer H, Valero V, Assad L, Poniecka A, Hennessy B, Green M, Buzdar AU, Singletary SE, Hortobagyi GN, Pusztai L (2007) Measurement of residual breast cancer burden to predict survival after neoadjuvant chemotherapy. J Clin Oncol 25: 4414-4422.

Vargo JA, Beriwal S, Ahrendt GM, Soran A, Johnson RR, McGuire K, Bhargava R (2011) Molecular class as a predictor of locoregional and distant recurrence in the neoadjuvant setting for breast cancer. Oncology 80: $341-349$.

Von Minckwitz G, Untch M, Blohmer JU, Costa SD, Eidtmann H, Fasching PA, Gerber B, Eiermann W, Hilfrich J, Huober J, Jackisch C, Kaufmann M, Konecny GE, Denkert C, Nekljudova V, Mehta K, Loibl S (2012) Definition and impact of pathological complete response on prognosis after neoadjuvant chemotherapy in various intrinsic breast cancer subtypes. J Clin Oncol 30: 1796-1799.

Wapnir IL, Anderson SJ, Mamounas EP, Geyer Jr CE, Jeong JH, Tan-Chiu E, Fisher B, Wolmark N (2006) Prognosis after ipsilateral breast tumor recurrence and locoregional recurrences in five National Surgical Adjuvant Breast and bowel Project node-positive adjuvant breast cancer trials. J Clin Oncol 24: 2028-2037.

Wolmark N, Wang J, Mamounas E, Bryant J, Fisher B (2001) Preoperative chemotherapy in patients with operable breast cancer: nine-year result from National Surgical Adjuvant Breast and Bowel Project B-18. J Natl Cancer Inst Monogr 30: 96-102.

(c) (1) (2) (2) This work is licensed under the Creative Commons Attribution-Non-Commercial-Share Alike 4.0 International License. To view a copy of this license, visit http:// creativecommons.org/licenses/by-nc-sa/4.0/

Supplementary Information accompanies this paper on British Journal of Cancer website (http://www.nature.com/bjc) 